\title{
Follicular dendritic cells display microvesicle-associated LMP1 in reactive germinal centers of EBV+ classic Hodgkin lymphoma
}

\author{
Stefania Uccini ${ }^{1}$ - Mazin F. Al-Jadiry ${ }^{2}$ Giuseppina Pepe ${ }^{3} \cdot$ Anna Pasquini $^{3}$ - Adel R. Alsaadawi ${ }^{4} \cdot$ Salma A. Al-Hadad $^{2}$. \\ Arianna Di Napoli ${ }^{3}$. Claudio Tripodo ${ }^{5,6} \cdot$ Luigi Ruco $^{3}$
}

Received: 12 December 2018 / Revised: 6 June 2019 / Accepted: 10 June 2019 / Published online: 15 June 2019

(C) The Author(s) 2019

\begin{abstract}
Expression of the latent membrane protein-1 (LMP1) of Epstein-Barr virus (EBV) was investigated in 153 cases of EBV+ classic Hodgkin lymphoma (cHL); 120 cases were pediatric patients ( $<14$ years of age) from Iraq, and 33 cases were adult patients from Italy. We describe for the first time the presence of LMP1 protein in EBV-encoded RNA (EBER)-negative follicular dendritic cells (FDCs) of reactive germinal centers $(\mathrm{GC})$ associated with $\mathrm{EBV}+\mathrm{cHL}$. Presence of $\mathrm{LMP} 1+\mathrm{GCs}$ was independent of geographic region and age of patients. Variable numbers of reactive GCs were present in $22.2 \%$ of cases (34 of 153), whereas LMP1 staining of FDCs was present in about a third of cases (10 of 34) with reactive GC. Most cases with LMP1+ GC were mixed-cellularity (MC) subtype, but some nodular sclerosis (NS) was also present. GC cells with LMP1+ FDCs were surrounded by numerous EBV-infected cells which were positive for EBER, LMP1, and CD30. Double immunolocalization analysis revealed that LMP1 was associated with CD63, an exosomal marker, and with CD21. The possibility is discussed that peri-follicular EBV-infected cells release LMP1 protein, perhaps through exosomes, and that the protein is then captured by FDCs and is presented to EBER-negative GC B cells.
\end{abstract}

Keywords Latent membrane protein-1 (LMP1) · Epstein-Barr virus (EBV) - Classic Hodgkin lymphoma (cHL) · Follicular dendritic cells (FDCs) $\cdot$ Programmed death ligand 1 (PD-L1) · Exosomes and microvesicles

\section{Introduction}

EBV generally establishes different forms of latency, depending upon the phenotype and the transcription factor repertoire of the infected cell [1]. Under pathological conditions, the viral latent gene expression varies in different tumors [2]. The viral latent

Luigi Ruco

luigi.ruco@uniroma1.it

Istituto Pasteur Italia, Rome, Italy

2 Children's Welfare Teaching Hospital, Baghdad College of Medicine, Baghdad, Iraq

3 Department of Clinical and Molecular Medicine, Pathology Unit, Sant'Andrea Hospital, Sapienza University, Via di Grottarossa 1035, 00189 Rome, Italy

4 Department of Pathology, Baghdad Medical City Complex, Baghdad, Iraq

5 Tumor Immunology Unit, University of Palermo, Palermo, Italy

6 Tumor and Microenvironment Histopathology Unit, the FIRC Institute of Molecular Oncology, Milan, Italy gene expression observed in nasopharyngeal carcinoma (NPC) and Hodgkin lymphoma (HL) is of intermediate type II latency and is characterized by expression of latent membrane protein-1 (LMP1) in tumor cells. In fact, using immunohistochemistry, it was demonstrated that LMP1 is present in Hodgkin/ReedSternberg (HRS) cells of EBV+ classic Hodgkin lymphoma (cHL) $[3,4]$. EBV infection precedes HRS cell transformation. When present in the host cell, LMP1 acts as a mimic of CD40 and may contribute to the survival of HRS cell precursors by constitutively activating several of the pathways, including NF$\mathrm{kB}$, JAK/STAT, and phosphatidylinositol3-kinase/AKT, known to be aberrantly activated in HRS cells [2]. Localization of LMP1 to peri-nuclear regions of the cell is believed to be necessary to mediate these signaling functions [5].

LMP1 has also been demonstrated to localize to internal Golgi and multi-vesicular bodies (MVB). In lymphoblastoid cell lines, LMP1 was shown to be released into the extracellular spaces, possibly associated with exosomes [6-8]. Exosomes are a population of small $(40-150 \mathrm{~nm})$ endocytically derived extracellular vesicles [9]. They are produced from inward budding events on the limiting membrane of late endosomal organelles, forming intra-luminal vesicles in MVB. Similar to 
mechanisms of egress used by viral particles, MVBs can fuse with the plasma membrane to release exosomes into the extracellular space [9]. In further studies, it was shown that LMP1 is co-localized with the late endosomal protein Lamp3/CD63 [10] and that CD63 has a role in regulating LMP1 exosomal packaging and vesicle production [9].

Exocytosis of MVB and the release of exosomes were previously described in $\mathrm{B}$ and $\mathrm{T}$ lymphocytes and macrophages. It was shown that preparations of LMP1-containing exosomes have an immunosuppressive effect since they inhibit proliferation of peripheral blood mononuclear cells. Moreover, it was suggested that exosomes containing LMP1 could exert an anti-proliferative effect in $\mathrm{cHL}$, thus allowing tumor cells to evade the immune system [10].

In the present report, we describe 10 cases of $\mathrm{EBV}+\mathrm{cHL}$ in which LMP1 protein was present in HRS cells and in CD21+/ EBV-encoded RNA (EBER)-negative follicular dendritic cells (FDC) of reactive germinal centers (GC) as well. Furthermore, co-localization of LMP1, CD63, and CD21 could be demonstrated. Our findings are consistent with the possibility that LMP1 is released by EBV-infected cells located around follicles, possibly via exosomes, and is eventually captured by FDCs of GCs.

\section{Materials and methods}

Formalin-fixed paraffin-embedded (FFPE) sections of 153 cases of $\mathrm{EBV}+\mathrm{cHL}$ were investigated for expression of LMP1 protein (Table 1$)$. The majority (120 cases) were pediatric $(<14$ years of age), first diagnosed at the Children's Welfare Teaching Hospital of Baghdad College of Medicine, Iraq, and then sent for a second opinion to the Pathology Unit of Sant'Andrea Hospital of Rome, Italy [11]. Relevant clinical data were available for all the cases. None of the children had clinical or laboratory evidence of immunodeficiency. Results obtained with EBV+ cHL of Iraqi children were compared with those of 33 Caucasian adult patients diagnosed in Rome, Italy. The study was performed in accordance with the Helsinki Declaration and was approved by the local (Iraq) Ethical Committee. In Italy, Institutional Review Board was obtained (EC no. 168/SA/2003).

\section{Immunoperoxidase staining}

Paraffin sections were immunostained for CD30 (UCS Diagnostics, Italy), CD3, CD20, (Novocastra, UK), CD79a, CD15, CD68, CD21, LMP1 (mouse clones CS1-4, IgG1 kappa), CD63, PD-L1 (22C3), and PD1 (DAKO, Denmark), PAX5 (Thermo Scientific, USA), using an automated immunostainer (OMNIS, Agilent, USA). The anti-LMP1 CS1-4 mAb is a widely used reagent to detect LMP1 protein in paraffin sections. CS14 was originally developed by Rowe et al. [12] from mice immunized with a beta-galactosidase fusion protein containing the carboxyl half of the B95.8 strain LMP sequence. We have controlled the specificity of CS1-4 with a pre-absorption experiment. CS1-4 mABs $(.023 \mathrm{mg} / \mathrm{mL})$ were pre-incubated with a 10-20-fold higher concentration of recombinant EBV-LMP1 protein, partial AA 185-366 (MyBioSource, California, USA) that contain the sequence used to generate CS1-4. Results indicated that pre-incubation with recombinant LMP1 protein was effective in abolishing the staining for LMP1 of FDCs and of EBV-infected HRS cells. Furthermore, the specificity of CS1-4 for EBV-LMP1 protein was supported by the presence of LMP $1+$ cells only in cases of EBV+ cHL (EBER+) and of EBER+ nasopharyngeal carcinoma; cases of cHL negative for EBV (EBER-negative) were consistently negative also when immunostained with CS1-4.

In situ hybridization for EBER was performed on paraffin sections using Epstein-Barr Virus (EBER) PNA Probe/ Fluorescein and FITC/HRP (DAKO, Denmark).

\section{Immunofluorescence staining}

Double-marker immunofluorescence analysis was performed on 4- $\mu \mathrm{m}$-thick FFPE tissue sections following deparaffinization
Table 1 EBV+ cHL with LMP1+ reactive $\mathrm{GCs}$

\begin{tabular}{|c|c|c|c|c|c|c|}
\hline Patients & n. & $\begin{array}{l}\text { Mean age } \pm \\
\text { SD }\end{array}$ & $\mathrm{M}: \mathrm{F}$ & $\begin{array}{l}\text { Histology } \\
\text { subtype }\end{array}$ & GC+ histology & $\begin{array}{l}\text { GC+/LMP1+ } \\
\text { histology }\end{array}$ \\
\hline $\begin{array}{l}\text { Children }<14 \text { years } \\
\text { o } \\
\text { f age* }\end{array}$ & 120 & $7.6 \pm 2.9$ & $3.6: 1$ & $\begin{array}{l}68 \mathrm{MC} \\
\quad(57 \%) \\
52 \mathrm{NS}(43 \%)\end{array}$ & $\begin{array}{l}27 / 120 \\
\quad(23 \%) * * \\
17 \mathrm{MC}(63 \%) \\
10 \mathrm{NS}(37 \%)\end{array}$ & $\begin{array}{l}8 / 120(6.7 \%) * * \\
7 \mathrm{MC}(88 \%) \\
1 \mathrm{NS}(12 \%)\end{array}$ \\
\hline $\begin{array}{c}\text { Adults }>14 \text { years } \\
\text { of age* }\end{array}$ & 33 & $53.5 \pm 16.8$ & $2: 1$ & $\begin{array}{l}22 \mathrm{MC} \\
(67 \%) \\
11 \mathrm{NS}(33 \%)\end{array}$ & $\begin{array}{l}7 / 33(21 \%) * * \\
5 \mathrm{MC}(71 \%) \\
2 \mathrm{NS}(29 \%)\end{array}$ & $\begin{array}{l}2 / 33(6 \%) * * \\
1 \mathrm{MC}(50 \%) \\
1 \mathrm{NS}(50 \%)\end{array}$ \\
\hline Total number & 153 & & & $\begin{array}{l}90 \mathrm{MC} \\
\quad(59 \%) \\
63 \mathrm{NS}(41 \%)\end{array}$ & $\begin{array}{l}34 / 153 \\
\quad(22 \%) * *\end{array}$ & $\begin{array}{l}10 / 153 \\
\quad(6.5 \%) * *\end{array}$ \\
\hline
\end{tabular}

*Pediatric cases were from Iraq; adult cases were Caucasian patients from Italy

**Number of positive cases/number of investigated cases 
Fig. 1 a Cervical lymph node of a 26-year-old male with partial involvement by $\mathrm{EBV}+\mathrm{cHL}$ NS subtype. Two small CD20+ GCs in the reactive portion of the lymph node (red circle) are intensely stained for LMP1. Stained cells have a dendritic morphology consistent with a FDC origin. In the HL lesion, numerous large cells have HRS morphology and are EBER+. b Cervical lymph node of an 8-yearold boy with CD20+ follicular hyperplasia and with a small focus (HL) of EBV+ cHL. In the area with follicular hyperplasia, a large LMP1+ reactive GC (red circle) is surrounded by numerous LMP1+ cells infected by EBV (higher magnification)

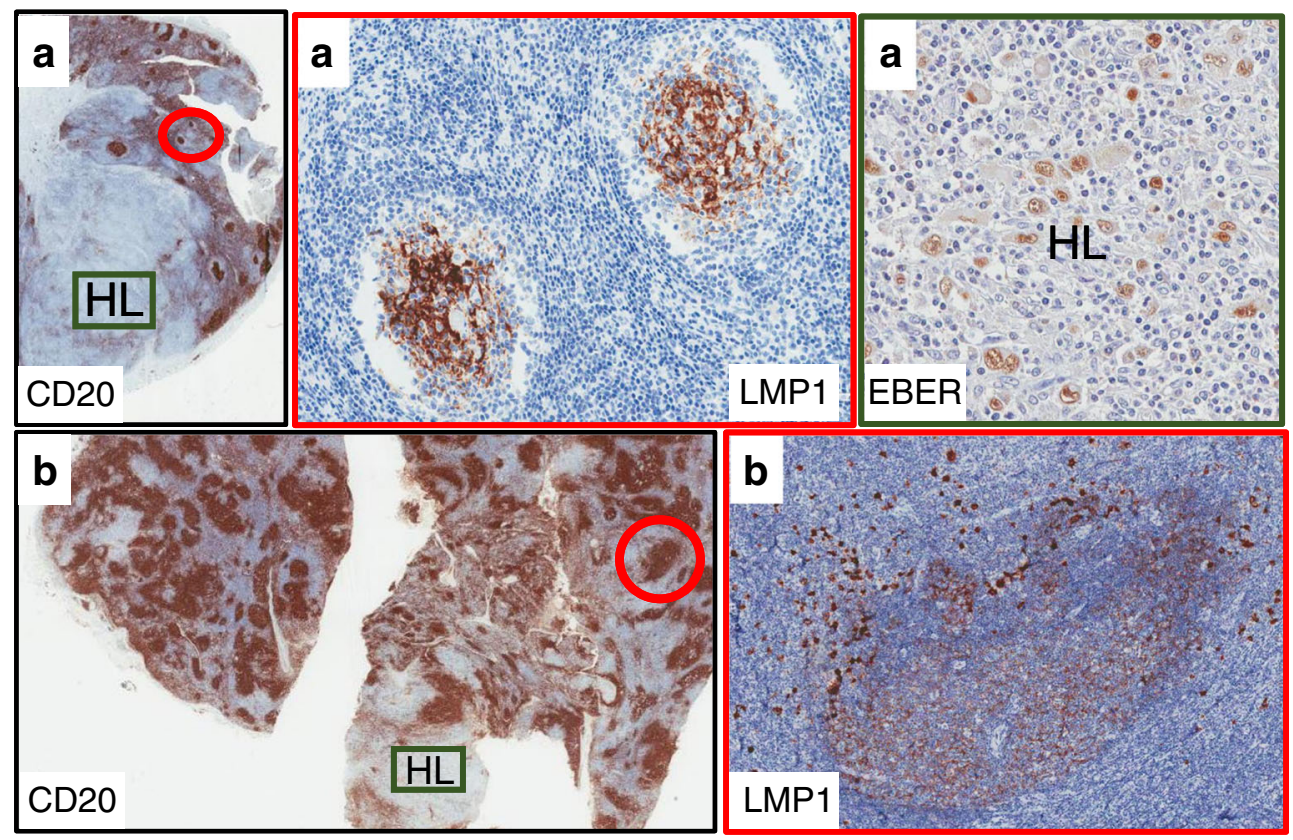

and heat-based antigenic retrieval as previously reported [13]. The sections were incubated overnight at $4{ }^{\circ} \mathrm{C}$ with the following primary antibodies: monoclonal anti-human LMP1 (clone CS1/CS4, 1:100 pH 9, Novocastra), monoclonal anti-human CD30 (clone Ber-H2, 1:20 pH 9, DAKO), monoclonal antihuman CD63 (clone EPR5702, 1:1000 pH 9, Abcam), polyclonal anti-human CD21 (760-4438, Ready-to-use, pH 9, Ventana). Bound antibodies were revealed by the following fluorochrome-conjugated secondary antibodies: Alexa Fluor 568 goat anti-mouse $\operatorname{IgG}(\mathrm{H}+\mathrm{L})(1: 300$ dilution) and Alexa Fluor 488 goat anti-rabbit $\operatorname{IgG}(\mathrm{H}+\mathrm{L})$ (1:250 dilution) both from Invitrogen Molecular Probes. Nuclei were counterstained with DAPI (4',6-diamidin-2-fenilindolo). For double-marker immunofluorescence stainings in which primary antibodies of the same made were adopted, the tyramide signal amplification system Opal Multiplex IHC kit (lot number 2395285, PerkinElmer Inc.) was used.

\section{Results}

\section{Immunohistochemistry}

Immunostaining for LMP1 protein was investigated in paraffin sections of 153 lymph nodes involved by EBV+ cHL. In all cases, the diagnosis of $\mathrm{cHL}$ was supported by focal or extensive lymph node effacement associated with presence of CD30+/ CD15+/LMP1+ HRS cells. An unexpected finding was the observation of LMP1 staining of FDCs in reactive GC cells of $6.7 \%$ (8/120) pediatric cases and of $6.0 \%$ (2/33) adult patients (Fig. 1). LMP1+ GCs were negative for EBER, thus suggesting that FDCs were not infected by EBV; however, numerous EBER+/
LMP1+ large cells surrounded and partially infiltrated the mantle zone of LMP1+ follicles (Fig. 2). Co-existence of reactive GCs and $\mathrm{EBV}+\mathrm{cHL}$ was further investigated (Table 1). It was found that variable numbers of reactive GCs were present in $22 \%$ of cases (34 of 153) and that LMP1 staining of FDCs was present in about a third of cases with reactive GCs (10 of 34). Most cases with LMP1+ GC were mixed-cellularity (MC) subtype, but some nodular sclerosis (NS) was also present. The extent of
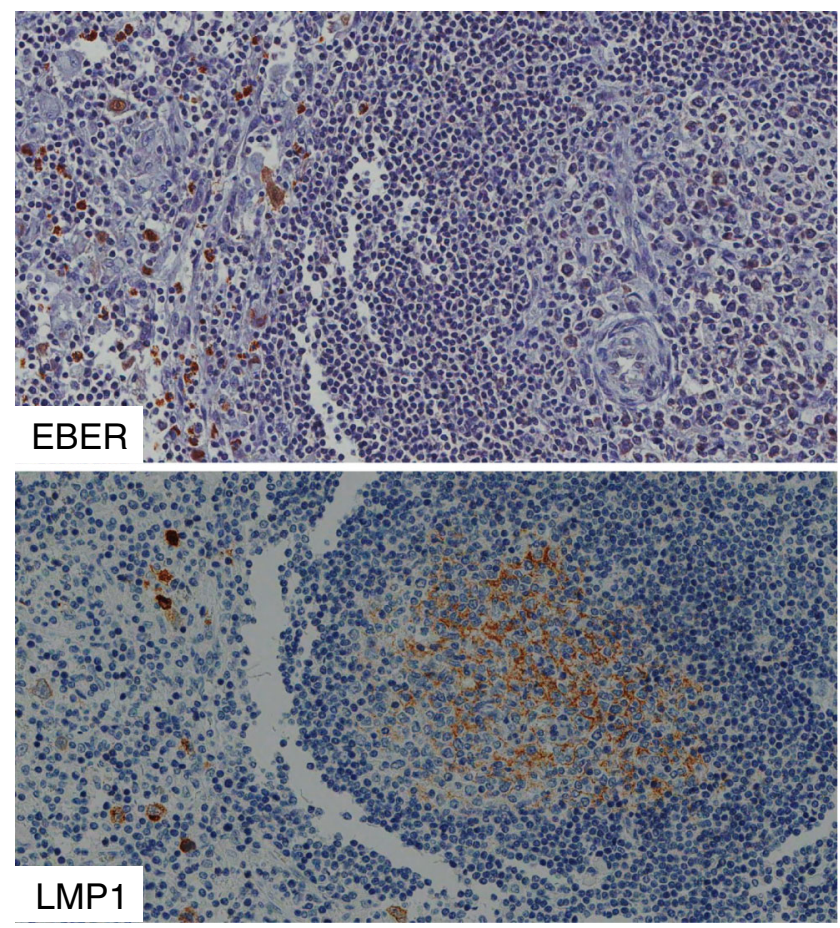

Fig. 2 EBV+ cHL with follicular hyperplasia. EBER+/LMP1+ large cells surround a B cell follicle with FDCs positive for LMP1 and negative for EBER 
LMP1+ follicular hyperplasia was variable and was predominant in some cases, with only a limited area of the lymph node showing evidence of cHL (Fig. 1). LMP1+ GCs were not observed in other EBV-related lymphoproliferative diseases, including 125 cases of EBV+ Burkitt lymphoma [14] and 7 cases of EBV+ DLBCL [15], which were previously investigated by our group.

A survey of the clinical-pathologic features of the eight pediatric cases of EBV+ $\mathrm{cHL}$ with LMP1+ GCs revealed that a possible distinguishing feature was a long time interval between onset of the disease and lymph node biopsy. In fact, this time was 11 months \pm 6 for the 8 cases with LMP1+ GC and 7 months \pm 7 for the remaining 112 cases $(p=0.028$; Mann Whitney test).

LMP1 protein has an immunosuppressive role [10]. Lymph node sections were immunostained for PD-L1 and for PD1. Immunostaining for PD-L1 was detected in HRS cells and in numerous macrophages as previously reported [16, 17]. PD1+ cells were very few in HL lesions. PD-L1+ cells were mostly located in lymph node sinuses, in inter-follicular areas and occasionally in peri-follicular areas encircling B cell follicles (Fig. 3). The peri-follicular distribution of PD-L1+ cells was observed around LMP1+ and LMP1-negative GCs as well. Moreover, peri-follicular PD-L1+ cells were not observed in 19 cases of EBV+ cHL lacking LMP1+ GCs and in 13 cases of EBV-negative cHL.

\section{Immunofluorescence}

The relation of LMP1 protein to FDCs was further investigated using double-marker immunofluorescence. It was confirmed that numerous CD21+ FDCs were double stained for LMP1 (Fig. 4). EBV-infected cells may release LMP1 protein using exosomes $[6,7]$, and CD63 is an exosome-associated protein $[9,18]$. Thus, lymph node sections were double stained for LMP1/CD63 or for
CD21/CD63 using immunofluorescence (Figs. 4 and 5). It was found that most stromal reticular cells, inside and outside GCs, were CD63+. Furthermore, it was found that some reticular cells inside GC were double stained for LMP1/CD63 and for CD21/CD63. These observations are consistent with the possibility that LMP1 and CD63 are released by peri-follicular EBER+/LMP1+ EBV-infected cells, perhaps through exosomes, and are then captured by FDCs.

\section{Discussion}

In the present report, we describe for the first time LMP1 protein in FDCs of reactive GCs present in cases of EBV+ cHL. LMP1+ FDCs were not infected by EBV (EBERnegative) and were present in a minority of cases (6\%); moreover, their presence was independent of histological subtype, age of patients, and geographic region. A longer time interval between onset of the disease and lymph node biopsy was a distinguishing feature of some cases with LMP1+ FDCs. It can be speculated that long persistence of EBV infection in the lymph node might represent one of the events which favor accumulation of LMP1 protein in FDCs. FDCs are also known as antigen-trapping cells because of their capacity of retaining and exposing antigen on their membranes for long periods of time [19]. Thus, long-lasting accumulation of the protein prior of biopsy might be the event which favored its detection by immunohistochemistry.

It is generally assumed that EBV infection of HRS cells precedes the development of EBV+ cHL [4]. However, little is known about the EBV-induced histological modifications which precede the development of $\mathrm{cHL}$. We have found that reactive GCs are present in $>20 \%$ cases of EBV+ cHL. Indeed, co-
Fig. 3 Immunostaining for PDL1 (clone 22C3) in two cases of $\mathrm{EBV}+\mathrm{cHL}$ with reactive GCs. Numerous intensely stained cells, probably macrophages, encircle B cell follicles
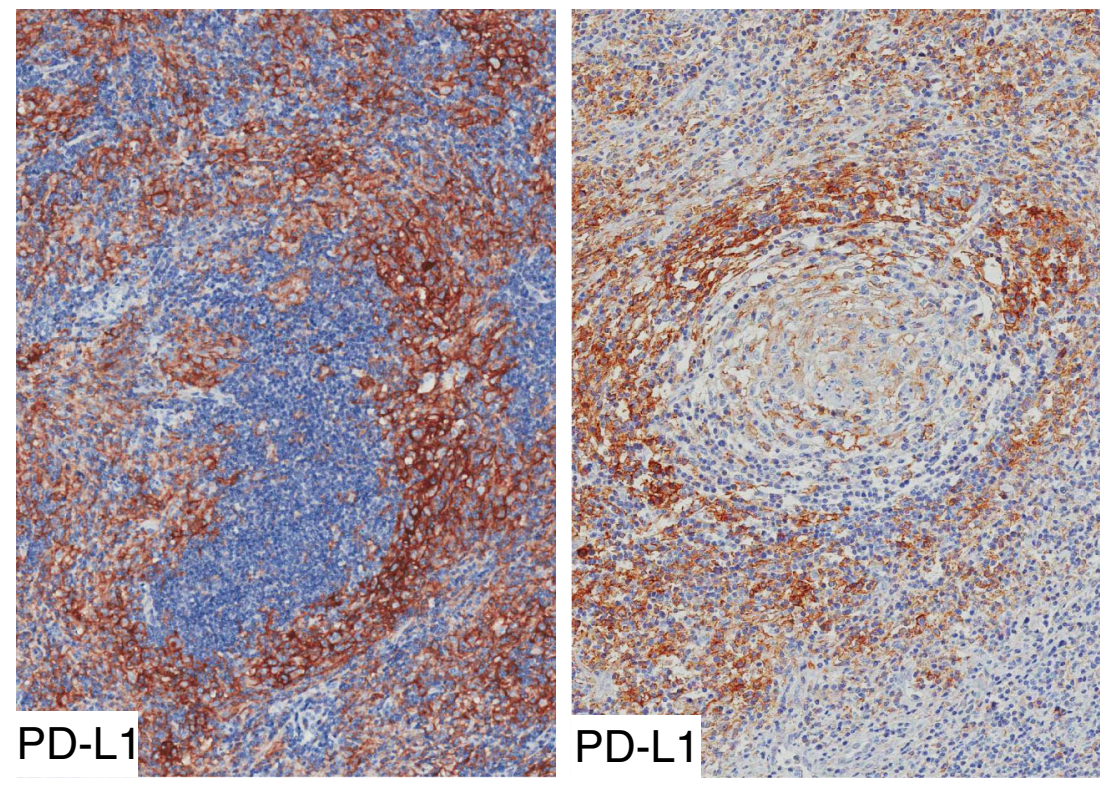
Fig. 4 Case 1. Numerous LMP1+ large cells surround and partially infiltrate B cell follicles with LMP1+ FDCs. Double staining with immunofluorescence confirmed the presence of perifollicular EBV-infected cells (LMP1+, red) and of CD21+ reticular FDCs (green). CD63, a marker for exosomes, was present in most stromal cells with reticular morphology inside and outside GCs. A high magnification of $\mathrm{GC}$ revealed the presence of double-positive cells (LMP1/CD63) with dendritic morphology
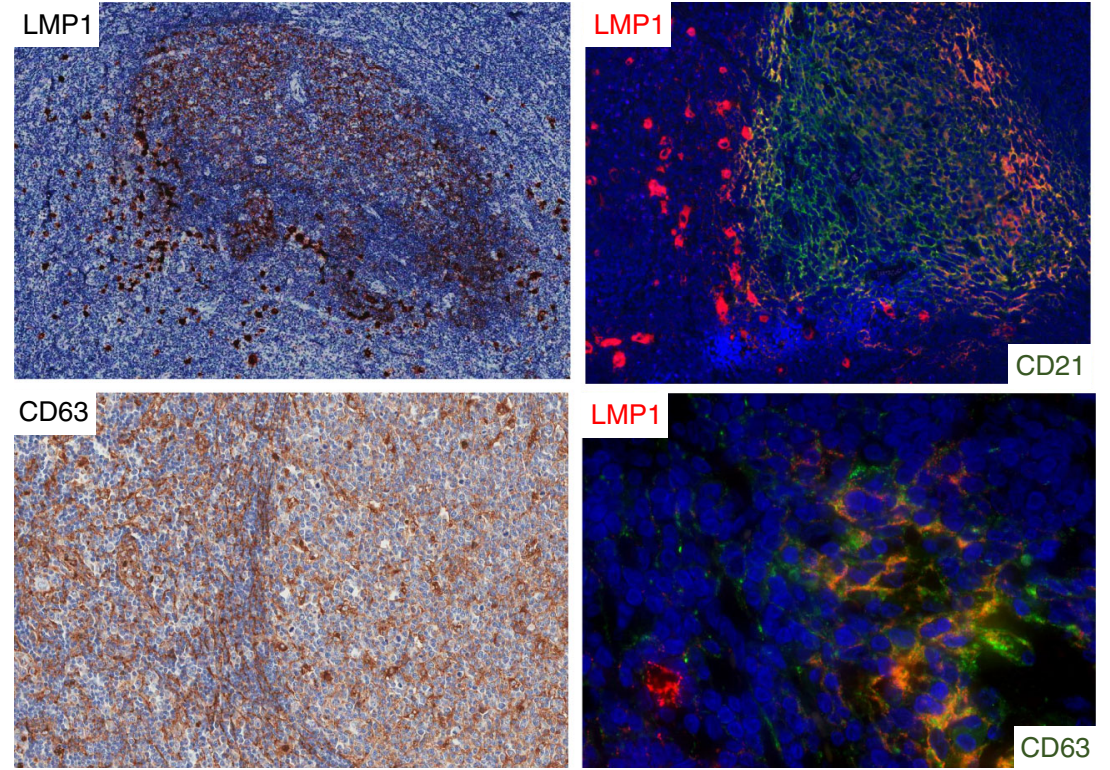

existence of follicular hyperplasia and $\mathrm{EBV}+\mathrm{cHL}$ was previously recognized [20], was defined inter-follicular cHL, and was interpreted as initial and partial involvement by $\mathrm{cHL}$ of a reactive lymph node. Our findings offer an alternative explanation. In fact, it can be speculated that cHL might develop in the background of a pre-existing EBV-related follicular lymphadenitis. Two lines of evidence support our interpretation. First, in some cases, LMP1+ reactive GCs were present throughout the lymph node whereas cHL was confined to a limited area (Fig. 1). Second, LMP1+ reactive GCs were often surrounded by CD30+ cells which were EBV-infected (EBER+/LMP1+). Some of them had HRS morphology, but others had a blast appearance and were of uncertain origin. Our findings are consistent with the possibility that two distinct events were occurring in the same lymph node: an EBV-related lymphadenitis, mainly involving B cell follicles, and a focal development of cHL.

It seems reasonable to postulate that LMP1 protein entrapped by FDCs was released by peri-follicular EBV-infected cells. It was previously demonstrated that EBV-infected cells may release exosomes containing LMP1 protein [6]. Exosomes are CD63+ endosomal-derived vesicles [8, 9] which transfer proteins, mRNAs, and microRNAs to neighboring or distant cells to modulate immune function, angiogenesis, cell proliferation, and tumor cell invasion. We have shown that LMP1+ FDCs were double stained for CD63 and CD21. Our observations support the view that LMP1 protein was associated with CD63+ exosomes released by perifollicular EBV-infected cells and captured by CD21+ FDCs.

Human tumor viruses utilize exosomes for intercellular communication [7]. It can be speculated that LMP1 released by EBV-infected cells may contribute to generation of the immunosuppressive microenvironment of cHL lesions. In fact, LMP1 may induce/enhance the production of proinflammatory and immunomodulatory cytokines such as IL6, IL-8, and IL-10 [5]. The relevance of the immunosuppressive microenvironment in $\mathrm{cHL}$ was recently highlighted by the beneficial effect of anti-PD1 immunotherapy. In the present study, we have observed that PD-L1 protein was present in
Fig. 5 A GC positive for LMP1 was double stained for CD21 (green) and for CD63 (red). Extensive areas of co-localization of the two signals (yellow) are present, thus suggesting that CD63 protein was associated with FDCs
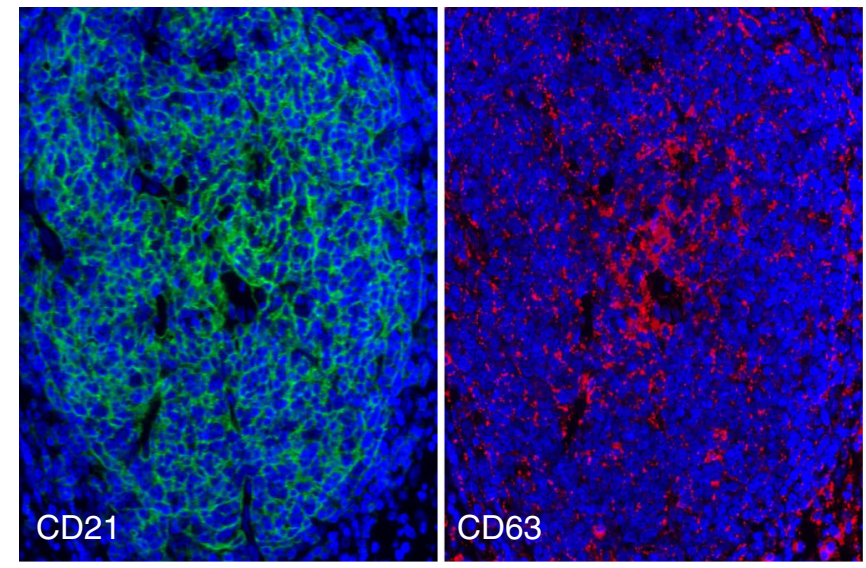
HRS cells and in macrophages as previously reported [16, 17], but we have also observed that PD-L1 was highly expressed in the inter-follicular and peri-follicular cells. This topographical link may indicate that $\mathrm{B}$ cell follicles represent one of the sites of spreading of regulatory signals which determine the immunosuppressive background of HL lesions.

Contributions Uccini made the original observation and reviewed 120 slides of Iraqi children. Di Napoli reviewed 33 Italian cases. Pepe is the post-doc in charge of the study. Pasquini gave technical support. Tripodo made the double-staining analysis. Alsaadawi made the histological diagnosis of Hodgkin lymphoma in Iraq. Al-Jadiry and Al-Hadad are pediatric oncologists who took care of the children in Iraq. Ruco designed the study and wrote the manuscript.

Funding The study was supported by a grant from the Istituto Pasteur Italia Fondazione Cenci Bolognetti and by a grant "Progetto di Cooperazione Internazionale Didattica e Scientifica con i paesi in via di sviluppo" from Sapienza University. The study is part of the collaborative scientific program "Baghdad Resolve" between Sapienza University and the Children's Welfare Teaching Hospital, Baghdad College of Medicine, Iraq.

\section{Compliance with ethical standards}

The study was performed in accordance with the Helsinki Declaration and was approved by the local (Iraq) Ethical Committee. In Italy, Institutional Review Board was obtained (EC no. 168/SA/2003).

Conflict of interest All authors declare that they have no conflict of interest.

Open Access This article is distributed under the terms of the Creative Commons Attribution 4.0 International License (http:// creativecommons.org/licenses/by/4.0/), which permits unrestricted use, distribution, and reproduction in any medium, provided you give appropriate credit to the original author(s) and the source, provide a link to the Creative Commons license, and indicate if changes were made.

\section{References}

1. Babcock GJ, Hochberg D, Thorley-Lawson AD (2000) The expression pattern of Epstein-Barr virus latent genes in vivo is dependent upon the differentiation stage of the infected B cell. Immunity 13:497-506

2. Vockerodt M, Yap LF, Shannon-Lowe C, Curley H, Wei W, Vrzalikova K, Murray PG (2015) The Epstein-Barr virus and the pathogenesis of lymphoma. J Pathol 235:312-322

3. Pallesen G, Hamilton-Dutoit SJ, Rowe M, Young LS (1991) Expression of Epstein-Barr virus latent gene products in tumour cells of Hodgkin's disease. Lancet 337:320-322

4. Stein H, Pileri SA, Weiss LM, Poppema S, Gascoyne RD, Jaffe ES (2017) Hodgkin lymphomas: introduction. In: Swerdlow SH, Campo E, Harris NL et al (eds) WHO classification of tumours of haematopoietic and lymphoid tissues, revised, 4th edn. IARC, Lyon, pp 424-430

5. Lam N, Sugden B (2003) LMP1, a viral relative of the TNF receptor family, signals principally from intracellular compartments. EMBO J 22:3027-3038

6. Flanagan J, Middeldorp J, Sculley T (2003) Localization of the EpsteinBarr virus protein LMP 1 to exosomes. J Gen Virol 84:1871-1879
7. Meckes DG Jr, Shair KH, Marquitz AR, Kung CP, Edwards RH, Raab-Traub N (2010) Human tumor virus utilizes exosomes for intercellular communication. Proc Natl Acad Sci U S A 107:20370-20375

8. Verweij FJ, van Eijndhoven MA, Hopmans ES, Vendrig T, Wurdinger T, Cahir-McFarland E, Kieff E, Geerts D, van der Kant R, Neefjes J, Middeldorp JM, Pegtel DM (2011) LMP1 association with CD63 in endosomes and secretion via exosomes limits constitutive NF-kB activation. EMBO J 30:2115-2129

9. Hurwitz SN, Nkosi D, Conlon MM, York SB, Liu X, Tremblay DC, Meckes DG Jr (2017) CD63 regulates Epstein-Barr virus LMP1 exosomal packaging, enhancement of vesicle production, and noncanonical NF-kB signaling. J Virol 91: e02251-16

10. Dukers DF, Meij P, Vervoort MB, Vos W, Scheper RJ, Meijer CJ, Bloemena E, Middeldorp JM (2000) Direct immunosuppressive effects of EBV-encoded latent membrane protein 1. J Immunol 165:663-670

11. Di Napoli A, Al-Jadiri MF, Talerico C, Duranti E, Pilozzi E, Trivedi P, Anastasiadou E, Alsaadawi AR, Al-Darraji AF, Al-Hadad SA, Testi AM, Uccini S, Ruco L (2013) Epstein-Barr virus (EBV) positive classical Hodgkin lymphoma of Iraqi children: an immunophenotypic and molecular characterization of Hodgkin/ Reed-Sternberg cells. Pediatr Blood Cancer 60:2068-2072

12. Rowe M, Evans HS, Young LS, Hennessy K, Kieff E, Rickinson AB (1987) Monoclonal antibodies to the latent membrane protein of Epstein-Barr virus reveal heterogeneity of the protein and inducible expression in virus-transformed cells. J Gen Virol 68:1575-1586

13. Tripodo C, Burocchi A, Piccaluga PP, Chiodoni C, Portararo P, Cappetti B, Botti L, Gulino A, Isidori A, Liso A, Visani G, Martelli MP, Falini B, Pandolfi PP, Colombo MP, Sangaletti S (2017) Persistent immune stimulation exacerbates genetically driven myeloproliferative disorders via stromal remodeling. Cancer Res 77:3685-3699

14. Uccini S, Al-Jadiry MF, Cippitelli C, Talerico C, Scarpino S, AlDarraji AF, Al-Badri SAF, Alsaadawi AR, Al-Hadad SA, Ruco L (2018) Burkitt lymphoma in Iraqi children: a distinctive form of sporadic disease with high incidence of $\mathrm{EBV}^{+}$cases and more frequent expression of MUM1/IRF4 protein in cases with head and neck presentation. Pediatr Blood Cancer 65:e27399

15. Uccini S, Al-Jadiry MF, Scarpino S, Ferraro D, Alsaadawi AR, AlDarraji AF, Moleti ML, Testi AM, Al-Hadad SA, Ruco L (2015) Epstein-Barr virus-positive diffuse large B-cell lymphoma in children: a disease reminiscent of Epstein-Barr virus-positive diffuse large B-cell lymphoma of the elderly. Hum Pathol 46:716-724

16. Carey CD, Gusenleitner D, Lipschitz M, Roemer MGM, Stack EC, Gjini E, Hu X, Redd R, Freeman GJ, Neuberg D, Hodi FS, Liu XS, Shipp MA, Rodig SJ (2017) Topological analysis reveals a PD-L1associated microenvironmental niche for Reed-Sternberg cells in Hodgkin lymphoma. Blood 130:2420-2430

17. Carbone A, Gloghini A, Carlo-Stella C (2018) Are EBV-related and EBV-unrelated Hodgkin lymphomas different with regard to susceptibility to checkpoint blockade? Blood 132:17-22

18. Pols MS, Klumperman J (2009) Trafficking and function of the tetraspanin CD63. Exp Cell Res 315:1584-1592

19. Aguzzi A, Kranich J, Krautler NJ (2014) Follicular dendritic cells: origin, phenotype, and function in health and disease. Trends Immunol 35:105-113

20. Zhou XG, Sandvej K, Li PJ, Ji XL, Yan QH, Zhang XP, Da JP, Hamilton-Dutoit SJ (2001) Epstein-Barr virus (EBV) in Chinese pediatric Hodgkin disease: Hodgkin disease in young children is an EBV-related lymphoma. Cancer 92:1621-1631

Publisher's note Springer Nature remains neutral with regard to jurisdictional claims in published maps and institutional affiliations. 